\title{
RELAÇÕES ANATÔMICAS DAS GLÂNDULAS PARATIREÓIDES CERVICAIS COM A TIREÓIDE: ESTUDO EM 53 TIREOIDECTOMIAS
}

\author{
ANATOMICAL RELATIONSHIPS OF THE CERVICAL PARATHYROIDS GLANDS WITH \\ THE THYROID: STUDY IN 53 THYROIDECTOMIES
}

\author{
João Bosco Botelho, TCBC-AM ${ }^{1}$; Gecildo Soriano dos Anjos ${ }^{2}$; Juber Machado Gomes Filho³; \\ Givanildo de Pádua Pires ; Daniele Memória Ribeiro Ferreira; \\ Fernando Bezerra de Melo e Souza ${ }^{6}$; Tarick de Oliveira Leite ${ }^{7}$
}

\begin{abstract}
RESUMO: Objetivo: O estudo foi transversal e retrospectivo por meio dos registros fotográficos, nos transoperatórios de 53 tireoidectomias totais e parciais, realizadas entre janeiro de 2002 a agosto de 2006, em pacientes portadores de doenças benignas e malignas da tireóide. Resultados: Foram obtidas imagens de 111 glândulas paratireóides. Das 67 superiores, 65 (97\%) estavam envolvidas pelo fino e irregular tecido adiposo peri-glandular. Das 44 inferiores, $41(93,1 \%)$ estavam parcial ou totalmente envoltas pela esparsa gordura aderida à cápsula tireóide. A escolha da via de acesso e o cuidado para evitar hemorragias são dois itens que evitam maiores dificuldades. Acrescem-se os rigores da técnica com a ligadura do pedículo superior, sendo realizada em primeiro lugar, seguida da mobilização do lobo tireóideo em sentido medial. Esses gestos possibilitam a melhor identificação das paratireóides. Conclusão: É indispensável conservar o tecido adiposo aderido à cápsula tireóidea, onde se alojam mais de $90 \%$ das paratireóides. O manuseio cirúrgico dessa delgada lâmina adiposa provoca a mudança da cor das paratireóides, tornando-as amarronzadas, destacando-as entre o amarelo-ouro da gordura e impondo maior atenção ao cirurgião (Rev. Col. Bras. Cir. 2008; 35(2): 072-078).
\end{abstract}

Descritores: Glândula paratireóide; Glândula tireóide; Tireoidectomia.

\section{INTRODUÇÃO}

Em 1880, Sandström descreveu numa revista sueca de circulação limitada as glândulas paratireóides inferiores humanas, uma de cada lado e próximas ao pólo inferior da tireóide. Sem que a comunidade científica tomasse conhecimento do trabalho do médico sueco, em 1891, Gley referiu as paratireóides inferiores em cachorros e coelhos. Em 1895, Kohn identificou as paratireóides superiores humanas ${ }^{1}$.

Nas décadas seguintes, eminentes anatomistas reproduziram os trabalhos de Sandström, Gley e Kohn e assentaram informações que influenciaram, decisivamente, a operação da tireóide na conservação das paratireóides, mudando o perfil das complicações pós-operatórias.

Este trabalho tem como objetivo estruturar um protocolo anatômico-cirúrgico para orientar os jovens cirurgiões no reconhecimento das relações entre as glândulas paratireóides cervicais em relação à glândula tireóide no curso das tireoidectomias parciais e totais.

\section{MÉTODO}

O estudo foi transversal e retrospectivo por meio dos registros fotográficos, nos transoperatórios de 53 tireoidectomias totais e parciais, realizadas pelo mesmo cirurgião, equipe cirúrgica e anestesiologista, entre janeiro de 2002 a agosto de 2006, em pacientes portadores de doenças benignas e malignas da tireóide.

Os procedimentos cirúrgicos seguiram com rigor a mesma rotina nos 53 pacientes:

1. A operação mínima foi a lobectomia total com istmectomia;

2. Escolha da incisão:

A - Nas doenças benignas:

a1. Se o bócio apresentava até $40 \mathrm{cms}^{3}$ no ultra-som, a incisão de Kocher foi a escolhida. Contudo, dependendo da localização do nódulo, para facilitar o acesso ao pedículo superior, a incisão variou poucos milímetros para cima em relação à fúrcula esternal (Figura 1-A);

1. Professor-Doutor; Pós-Doutor e Livre Docente da Disciplina de Otorrinolaringologia-Cirurgia Cervico-Facial da UEA e do UNINILTON LINS; Chefe do Serviço, Professor Convidado do Serviço de ORL-CCF do CHU Bichat-Claude Bernard da Universidade de Paris VII (UP VII); Professor Titular aposentado da Universidade Federal do Amazonas (UFAM).

2. Professor-Mestre e Doutorando do Programa Multi-Institucional de Pós-Graduação em Biotecnologia da UFAM / UP VII, da Disciplina ORL-CCF do UNINILTON LINS; Preceptor das Residências em ORL do HSJ e do Hospital Adriano Jorge (HAJ-UEA).

3. Chefe do Serviço de Anestesiologia do HSJ.

4. Preceptor da Residência em ORL do HSJ e ex-Residente em ORL do HSJ.

5. Médica Residente-R3 em ORL do HSJ.

6. Médico Residente-R2 em ORL do HSJ

7. Aluno do $6^{\circ}$ ano do Curso de Medicina do UNINILTON LINS e bolsista da FAPEAM.

Recebido em 28/09/2007

Aceito para publicação em 26/11/2007

Conflito de interesses: nenhum

Fonte de financiamento: Fundação de Amparo à Pesquisa do Amazonas (FAPEAM).

Primeiro lugar no Programa de Iniciação Científica-2007 do UNINILTON LINS.

Trabalho realizado no Serviço de Otorrinolaringologia-Cirurgia Cervico-Facial e Residência Médica em Otorrinolaringologia do HSJ e Hospital Santa Júlia (HSJ), Centro Universitário Nilton Lins (UNINILTON LINS) e Universidade do Estado do Amazonas (UEA). 
a2. Com mais de $40 \mathrm{cms}^{3}$, foi utilizada a incisão em $\mathrm{U}^{9,10}$ (Figura 1-C).

a3. Como opção intermediária entre as duas, dependendo do tamanho do bócio e da localização do(s) nódulo(s) junto ao pedículo superior, é factível a incisão arciforme ${ }^{19}(\mathrm{Fi}-$ gura 1-B). Como a de Kocher, também pode ter o ponto central que ampara os braços laterais mais poucos milímetros acima da fúrcula, para que a dissecção do retalho cranial facilite a abordagem do pedículo superior. Nos bócios cervicomediastínicos que não foi possível a exérese por via cervical, utilizou-se a variável da incisão em $\mathrm{U}$, com componente vertical descendente, médio-esternal, até o $4^{\circ}$ ou $5^{\circ}$ espaço intercostal, em dependência da posição do bócio no mediastino anterior (Figura 1-D).

B. Nas doenças malignas:

- O critério foi semelhante, mas quando houve indicação do esvaziamento cervical uni ou bilateral, independente do tamanho do tumor, usou-se a incisão em U.

As dissecções dos retalhos com bisturi elétrico, sob o músculo platisma, obedeceram aos seguintes limites: A. Na incisão de Kocher (Figura 2-A): - Superior: no mínimo, na porção central da cartilagem tireóidea da laringe; - Lateral direito e esquerdo: a borda medial do músculo esternocleidomastóideo liberada da musculatura infrahióidea; - Inferior: fúrcula supra-esternal livre. B. Na incisão arciforme (Figura 2-B). Critérios semelhantes aplicados à incisão de Kocher. C. Na incisão em U e na variante com componente esternal (Figuras 2-C, D): - Superior: até a membrana tireo-hióidea; - Lateral direita e esquerda: até a borda lateral do músculo esternocleidomastóideo; - Inferior: fúrcula supra-esternal livre.

Os dados obtidos foram transpostos ao desenho esquemático, modificado de $\mathrm{Abboud}^{2}$, para assentar as relações anátomo-cirúrgicas das paratireóides cervicais em relação às tireóides.

Critérios de inclusão: pacientes portadores de doenças da tireóide, benignas e malignas, que receberam indicação para tireoidectomia total ou parcial.
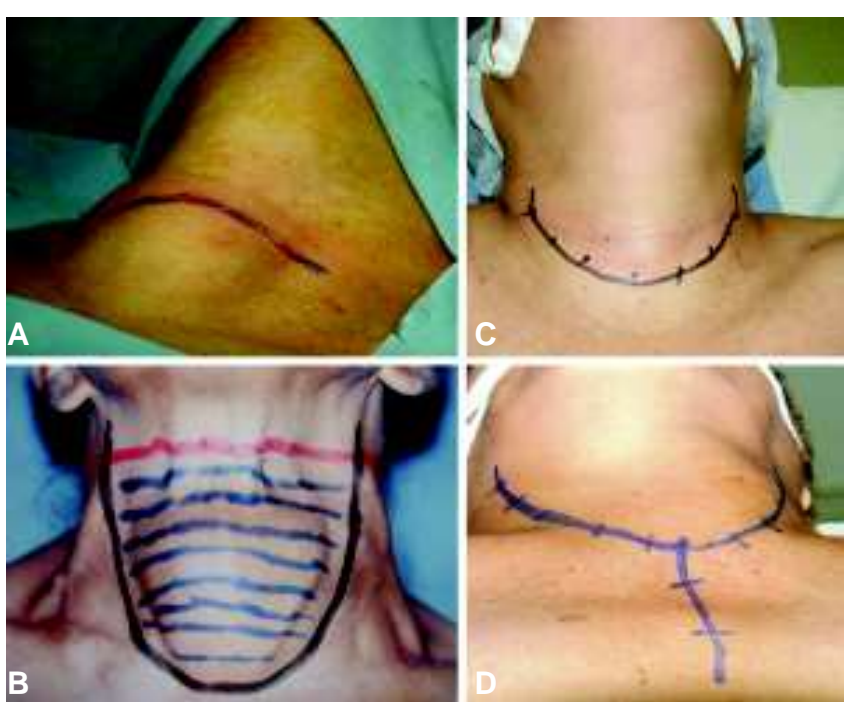

Figura 1 - A: Incisão de Kocher mais distante da fúrcula esternal para facilitar o acesso ao pedículo superior; B: Incisão arciforme; C: Incisão em $U ; \boldsymbol{D}$ : Variante da incisão de U com componente médio-esternal até o $4^{0}$ espaço intercostal.
Foram excluídos os pacientes submetidos às tireoidectomias parciais ou totais sem registros fotográficos e os nos quais as imagens não ficaram adequadas.

\section{RESULTADOS}

O total de 53 pacientes foi submetido às tireoidectomias, sendo: 39 totais $(73,6 \%)$ e 14 parciais $(26,4 \%)$. As tireoidectomias parciais significaram as lobectomias totais com istmectomias: oito à esquerda $(15,1 \%)$ e seis à direita $(11,3 \%)$.

Foram obtidas imagens de 111 glândulas paratireóides, com distribuição percentual e topográfica apresentadas na Figura 3.

Paratireóides superiores: 67 com identificação fotográfica. A maior parte, 65 (97\%) se mostrou não mais de um e meio centímetro abaixo do pólo superior da tireóide e sem relações topográficas com o pedículo. Só foi possível isolálas do esparso tecido adiposo pericapsular (Figura 4) após as ligaduras das artérias tireóideas superiores e inferiores e a completa mobilização do lobo em direção medial (Figuras 5 e 6). Mesmo em pequena proporção, dois (3\%) foram localizadas acima da tireóide, medialmente ao pedículo (Figura 7-D).

Paratireóides inferiores: 44 com identificação fotográfica. A maior parte, 34 (77,2\%) foi dissecada contigua e ao longo do terço inferior do lobo tireóideo, na face posterior, parcial ou completamente envolta pelo tecido esparso adiposo contíguo à cápsula da tireóide (Figura 4), apresentando muitas variáveis relacionadas com as artérias tireóideas inferiores (Figura 6). Todavia, 10 (22,8\%) foram identificadas contíguas à porção média do lobo tireóideo, sem significante relacional com a artéria tireóidea inferior.
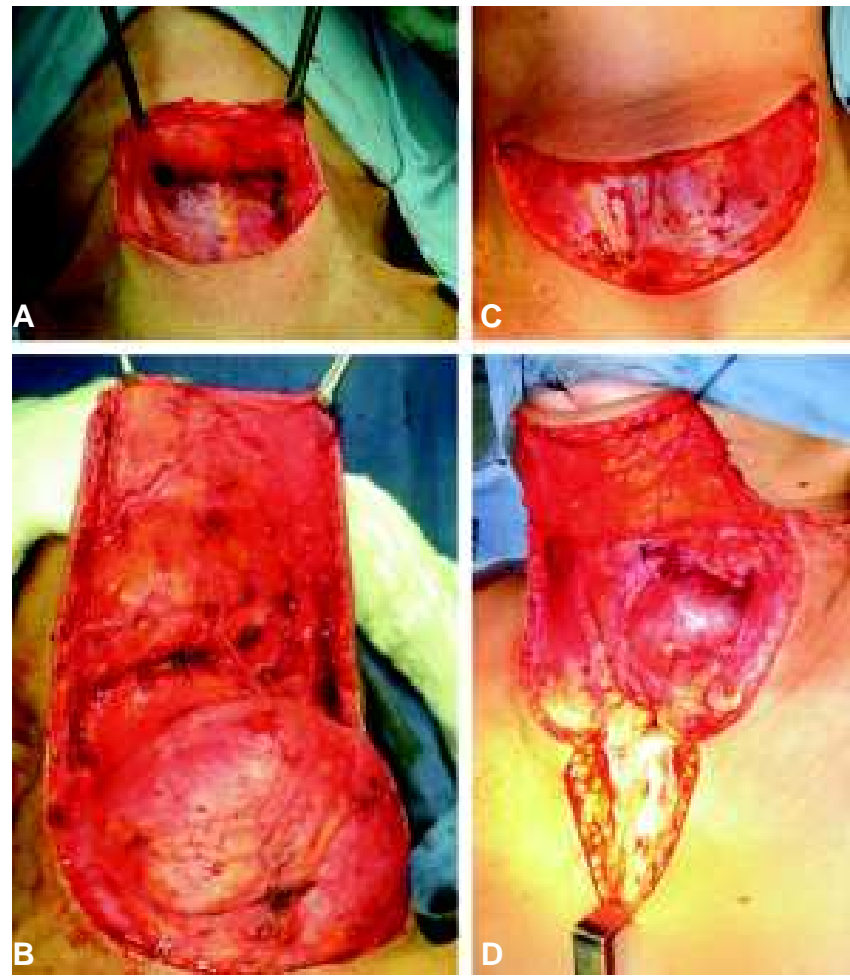

Figura 2 - A: Dissecção dos retalhos na incisão de Kocher; B: Na incisão arciforme; $\boldsymbol{C}:$ Na Incisão em $U ; \boldsymbol{D}:$ Na variante da incisão em U com componente esternal. 


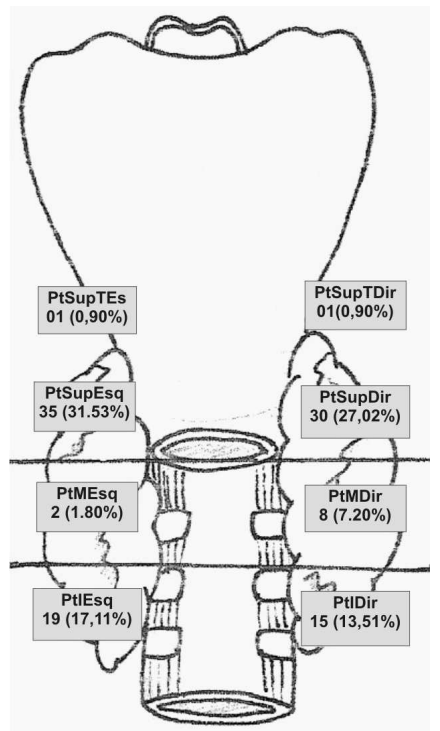

Figura 3 - Localizações das 111 paratireóides em relação à face posterior da tireóide.

PtSupTEsq-Paratireóide superior à tireóide esquerda; PtSupTDirParatireóide superior à tireóide direita; PtSupEsq - Paratireóide superior esquerda; PtSupDir-Paratireóide superior direita; PtMEsq - Paratireóide média esquerda; PtMDir-Paratireóide média direita; PtIEsq-Paratireóide inferior esquerda; PtIDir - Paratireóide inferior direita.

\section{DISCUSSÃO}

Mais de cem anos após a descrição anatômica das paratireóides humanas continua não sendo fácil ao jovem cirurgião identificá-las e preservá-las no curso das tireoidectomias. Dessa forma, torna-se necessário construir parâmetros que possam explicar a dificuldade e acrescentar dados e alternativas para superar os obstáculos.

As topografias anatômicas das paratireóides contidas nos clássicos de anatomia, oriundas de cadáveres formalizados e sem doença na tireóide, evidencia substancial desacordo aos achados no curso das tireoidectomias ${ }^{3,4,5}$. Por outro lado, o estudo das paratireóides em cadáveres frescos sem bócios mostrou que as localizações, tamanhos e cores se aproxima muita mais dos achados cirúrgicos ${ }^{6,7}$.

Existem várias contradições entre a realidade cirúrgica, nas tireoidectomias, com os livros de anatomia. Uma das mais relevantes é a presença das artérias paratireóides, descritas em pormenores nesses compêndios, mas nem sempre identificadas tanto em cadáveres não formalizados quanto no curso das tireoidectomias ${ }^{2,6,7,8}$.

O confronto de informações, em grande parte responsável pelos estorvos do jovem cirurgião, tem muitas variáveis. Assume especial destaque as mudanças topográficas determinadas nas paratireóides cervicais nos diferentes tipos de aumento do volume da glândula tireóide, em especial, nos bócios de grande volume ${ }^{9,10}$

A prevalência do hipoparatireoidismo após as tireoidectomias continua muito variável ${ }^{6,7,11-16}$. As causas do desacordo também são numerosas. Entre outras determinantes, é possível incluir: adestramento das equipes de cirurgiões e
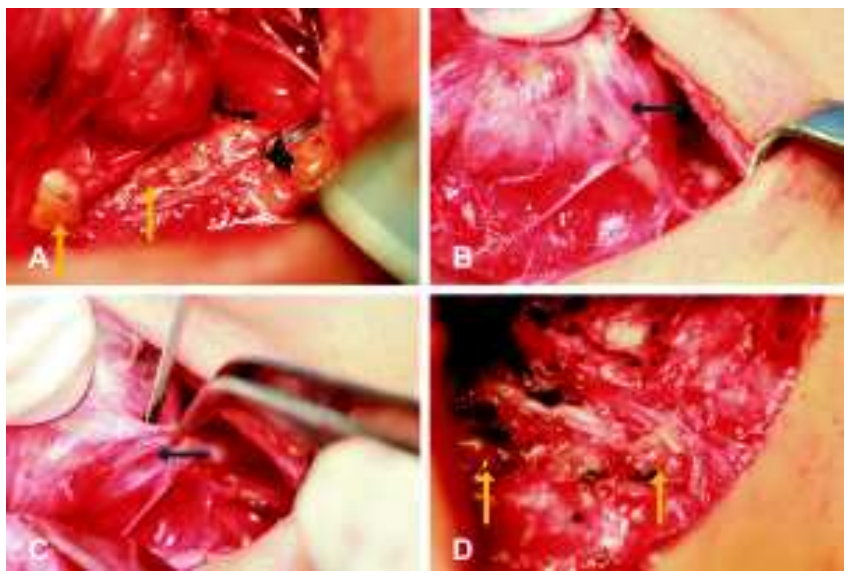

Figura 4-A, D: Paratireóides inferiores: parcial ou totalmente encobertas pelo tecido adiposo irregular junto à cápsula da tireóide (seta amarela); B, $\boldsymbol{C}$ : Preservação cuidadosa do tecido adiposo esparso e irregular junto à cápsula tireóidea na porção posterior do lobo (seta preta).

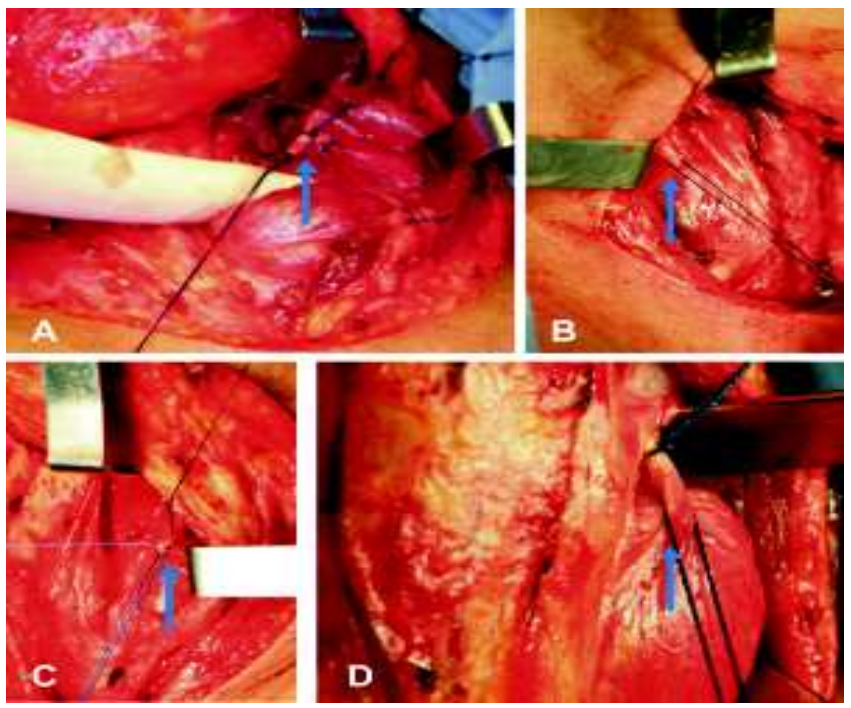

Figura 5-A, B, C, D - Ligaduras das artérias tireóideas superiores ( seta azul) em posições mais mediais e anteriores em relação à veia tireóidea superior.

anestesiologistas, qualidade da estrutura hospitalar, tipo de tireoidectomia (parcial ou total), segunda tireoidectomia (totalização da operação parcial no câncer e na recidiva de bócio), nas neoplasias malignas com diagnóstico pré-operatório firmado por meio da punção aspirativa de agulha fina nas quais existe a indicação do $\mathrm{I}^{131} \mathrm{em}$ dose terapêutica e nesses casos, quando presente, também, a exérese em monobloco do processo piramidal e, finalmente, nas operações associadas (esvaziamento cervical uni ou bilateral funcional ou radical), pescoço previamente irradiado e doente obeso com o pescoço curto.

Sob o estigma do hipoparatireoidismo pós-operatório, a "tireoidectomia sub-capsular" ganhou muitos adeptos após a publicação de Thompson ${ }^{17}$, retomando a abordagem cirúrgica entre a cápsula da tireóide e a artéria tireóidea inferior. Numa série de 315 tireoidectomias parciais, que incluíam lobectomias totais e lobectomias parciais bilaterais, esse autor não assinalou hipoparatireoidismo e nem lesão do nervo laríngeo recorrente. Todavia, em 96 tireoidectomias totais, dois 
pacientes apresentaram hipoparatireoidismo permanente e três apresentaram lesões do nervo laríngeo recorrente.

Pela absoluta limitação nas doenças nodulares bilaterais, mais prevalentes nas áreas geográficas bociogênicas, como no Amazonas ${ }^{18}$, e nas neoplasias malignas, a "tireoidectomia sub-capsular" está cada vez mais em desuso. Desse modo, a proposta de Thompson também não se mostra como solução para evitar o hipoparatieoidismo nas operações da tireóide.

Os vetores de múltiplas variáveis, para identificar as paratireóides no curso das tireoidectomias, impõem uma longa curva de aprendizado na formação dos jovens cirurgiões, especialmente, nas doenças nodulares que alcançam os dois lobos quando a tireoidectomia total é indispensável. De maneira mais enfática, nas neoplasias malignas com linfonodos metastáticos regionais uni ou bilaterais, ocasião em que os esvaziamentos cervicais se tornam imperativos. Sem dúvida, as publicações evidenciam maior possibilidade de hipoparatireoidismo no pós-operatório das tireoidectomias totais e nas complementadas pelos esvaziamentos cervicais, sem mudanças significativas nos últimos quinze anos ${ }^{11-16}$.

A técnica das tireoidectomias, no Brasil, foi magistralmente descrita pelo Prof. Mariano de Andrade ${ }^{19}$, em 1947, na tese que concorreu à Cátedra de Técnica Operatória e Cirurgia Experimental da Faculdade Nacional de Medicina da Universidade do Brasil. Este histórico trabalho conseqüente a uma grande experiência nessa operação, na Santa Casa de Misericórdia do Rio de Janeiro e no Hospital da Cruz Vermelha, fixou regras ao acesso cirúrgico da tireóide.

Contudo, como o nosso trabalho foi desenvolvido na Amazônia, incluída como área geográfica bociogênica pela Organização Mundial da Saúde, com importante prevalência dos bócios de grande volume, incluindo os bócios cervicomediatínicos ${ }^{9,10,18}$, houve a absoluta necessidade de mudanças na via de acesso, incluindo a mobilidade da clássica incisão de Kocher para mais cranialmente em relação à fúrcula esternal e o acréscimo das incisões em U e arciforme. Com essas mudanças, foi possível estabelecer com maior rigor as relações anatômicas entre as glândulas paratireóides cervicais e a tireóide.

De modo geral, nos países do Primeiro Mundo, em conseqüência da melhoria da atenção primária à saúde, os bócios de grande volume são muito raros. Ao contrário, na Amazônia, alcançam significativa prevalência ${ }^{18}$.

A experiência evidenciou a inadequação da incisão de Kocher a esses bócios. A solução ocorreu com a incisão em U. Essa via de acesso tem início no ponto de junção entre a imaginária linha horizontal passando pela borda superior da cartilagem tireóidea da laringe com a borda ventral do músculo esternocleidomastóideo bilateralmente, à esquerda ou à direita, descendente ao longo da borda muscular até a fúrcula esternal, onde ascende, terminando contralateral mente no mesmo limite, tomando a forma de $\mathrm{U}$ de concavidade cranial e tendo o platisma incisado no mesmo tamanho do retalho como limite profundo ${ }^{9,10}$.

O tempo cirúrgico torácico foi executado pelo cirurgião cardiovascular; nas circunstâncias em que o cirurgião teve dúvida se seria possível a retirada do bócio por via cervical, contou com a presença desse profissional e os instrumentos necessários à esternotomia preparados na sala de operação.
A partir da obtenção do plano anatômico correto na incisão, isto é, com o platisma incisado, os retalhos superiores e inferiores, nas três vias de acessos, são facilmente obtidos, ainda mais nos pacientes com mais de cinqüenta anos, com a dissecção romba, podendo ser por meio de uma gaze no dedo indicador do cirurgião, sob o platisma, até os limites desejados, se possível com a preservação das veias jugulares anteriores, que determinam o limite profundo do retalho. As traves fibrosas que aderem o platisma ao fáscia cervical médio, mais comuns dos jovens, devem ser seccionadas com o bisturi elétrico.

O pedículo superior era sempre ligado em primeiro lugar, após a tração firme e delicada do lobo tireóideo em
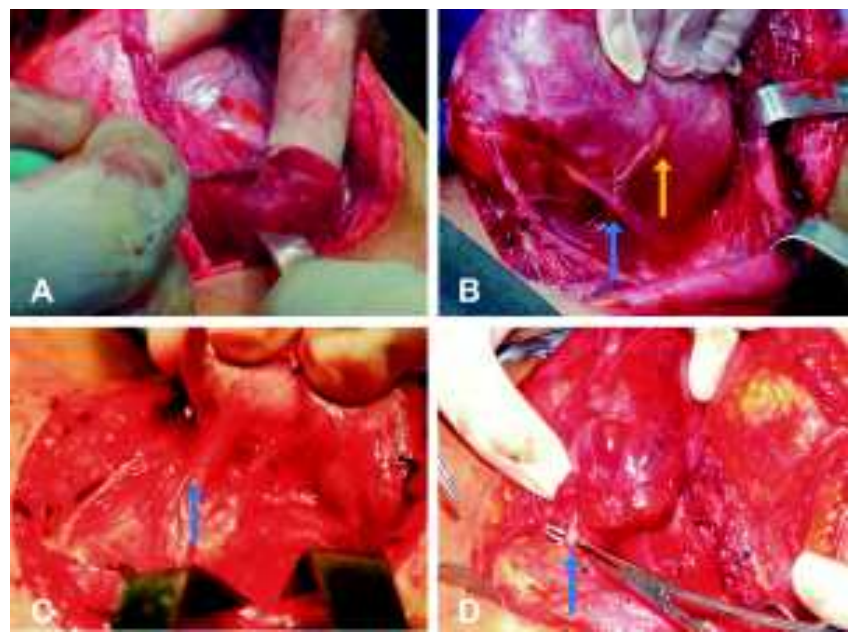

Figura 6-A: Miotomia da musculatura infra-hióidea para facilitar a mobilização do bócio de grande volume em direção medial; $\boldsymbol{B}, \boldsymbol{C}$ : Artérias tireóideas inferiores cruzando perpendicular e profundamente o terço inferior do lobo paratireóide (seta amarela); D: Artéria tireóidea inferior no bócio cérvico-torácico em posição mais inferior e junto ao pólo inferior do lobo tireóide.

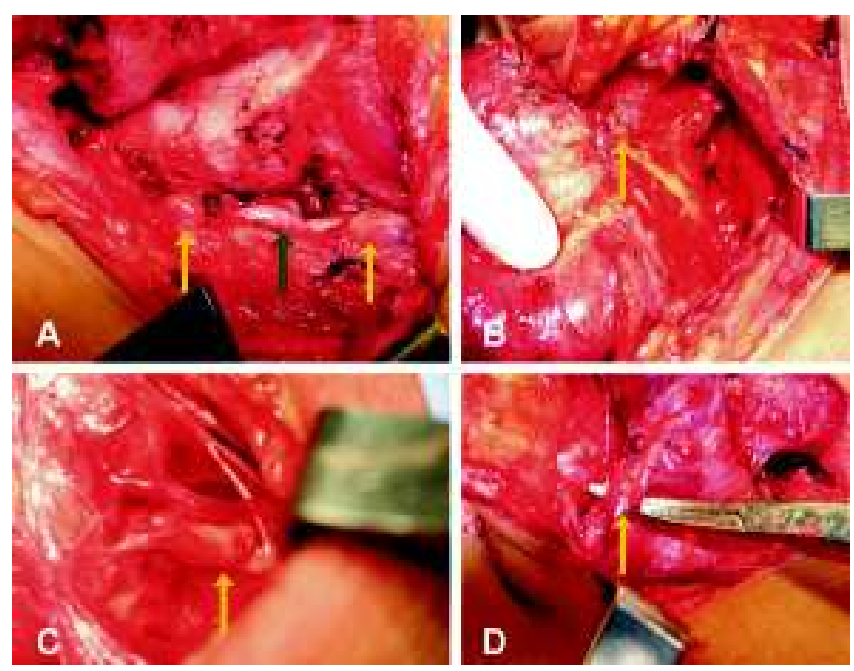

Figura 7-A: Paratireóide superior (seta amarela a direita) abaixo do pólo superior do lobo tireóide, paratireóide inferior (seta amarela a esquerda) e o nervo laríngeo recorrente (seta verde); B: Paratireóide superior (seta amarela) abaixo do pólo superior do lobo tireóide; $\boldsymbol{C}: A$ única paratireóide superior (seta amarela) que apresentou vascularização identificável, mas sem relação com a descrição dos livros de anatomia; D: Paratireóide acima do pólo superior do lobo tireóideo (seta amarela) contígua à artéria tireóidea superior. 
direção caudal e os afastamentos das bordas laterais dos músculos omo-hióideo e esterno-hióideo e da medial do esternocleidomastóideo. Em alguns pacientes, a inserção hióidea do músculo omo-hióideo se fazia mais lateral, pondo-se exatamente sobre o pedículo, obrigando a secção de fibras com atenção, sempre afastadas do conteúdo abaixo delas, para a visualização da artéria tireóidea superior. Um dos fatos importantes nesse processo de desvendar anatômico-cirúrgico foi a constatação de que a artéria e veia tireóideas, diversa do descrito nos livros de anatomia, raramente estavam próximas entre si, o predominante foi a artéria tireóidea superior mais anterior e medial em relação à veia (Figura 5). Independente dessa situação, a ligadura da artéria tireóidea superior foi realizada de imediato e a da veia tireóidea superior, em alguns pacientes, só após a ligadura da artéria tireóidea inferior, quando foi possível a completa mobilização do lobo em direção medial. É razoável argumentar que esse desacordo com os clássicos de anatomia ${ }^{3,4,5}$ seja conseqüência das mudanças topográficas promovidas pelo tamanho do bócio. Nos bócios de grande volume e nos em que o(s) nódulo(s) está próximo ou sobre o pólo superior do lobo tireóideo forçam o crescimento em direção cranial, impondo maior separação entre a artéria e a veia tireóideas. Esse argumento é anatomicamente justificado: enquanto a artéria se posiciona medialmente; a veia, lateralmente, fazendo com o crescimento do bócio amplie a distancia entre esses vasos e encurte a distância entre a artéria tireóidea superior e a artéria carótida externa. Essa é a razão principal para que a incisão privilegie maior facilidade na abordagem do pedículo superior.

Após a ligadura do pedículo superior, a mobilização do lobo tireóideo em direção medial é realizada sem transtorno. Se o tamanho do bócio de grande volume impede esse gesto, a miotomia transversa da musculatura infrahióidea facilitará a abordagem (Figura 6-A). Esse conjunto que interage técnica e tática permite o reconhecimento imediato da artéria tireóidea inferior e, no mesmo tempo cirúrgico, o do nervo laríngeo recorrente e o das paratireóides superiores inferiores. O outro desacordo com os clássicos de anatomia é quanto a topografia artéria tireóide inferior. Enquanto os anatomistas insistem que a entrada desse vaso na tireóide se faz junto ou mais próximo à porção caudal do lobo ${ }^{3,4,5}$, em nenhum dos pacientes deste trabalho foi confirmada essa topografia: as artérias tireóideas inferiores cruzaram perpendicularmente o campo cirúrgico, profundamente ao lobo, penetrando no terço inferior à tireóide (Figura 6B, C). A explicação anatômica é semelhante ao que acontece com a artéria tireóide superior, mas com resultante diferente: o crescimento do bócio afasta a artéria do pólo inferior e aumenta a distância da artéria subclávia. A exceção ocorre nos bócios cervico-mediastínicos, onde o crescimento do bócio em direção caudal, mantém a artéria tireóidea inferior junto ao pólo inferior do lobo tireóideo (Figura dD). Em qualquer das posições, se essa artéria estiver exposta de modo adequado poderá ser ligada com segurança sem probabilidade de lesão do nervo laríngeo recorrente. Quanto a topografia da veia tireóidea inferior foi a que mais se aproximou da dos livros de anatomia; em todos os paci- ente, esse vaso foi dissecado no pólo inferior do lobo tireoidiano.

A topografia das glândulas paratireóides no curso das tireoidectomias constitui outra discrepância com os tratados de anatomia. Em absoluto desacordo com os anatomistas que descrevem as paratireóides isoladas, no chamado compartimento tireóideo ${ }^{3}$, com vascularização específica e detalhada, os achados dessa série foram os seguintes:

- Superiores: das 67 paratireóides superiores identificadas, $60(89,5 \%)$ estavam envolvidas pelo fino e irregular tecido adiposo peri-glandular (Figura 4). De modo invariável, durante o manuseio cirúrgico, as paratireóides mudaram imediatamente a cor levemente acinzentada para a amarronzada. Esse fato é o mais relevante no reconhecimento das paratireóides. Somente em um paciente $(1,5 \%)$ foi possível identificar com clareza a vascularização da paratireóide (Figura 7-C), também situada abaixo do pólo superior do lobo, mas sem relação com as artérias tireóideas superior ou inferior, como afirmam os clássicos de anatomia ${ }^{3,4,5}$.

- Inferiores: das 44 paratireóides inferiores identificadas, $41(93,1 \%)$ igualmente às superiores, estavam parcial ou totalmente envoltas pela esparsa gordura aderida à cápsula tireóide. Também do mesmo modo que as superiores, no manuseio cirúrgico, com objetivo de liberar o lobo do tecido adiposo esparso e irregular contíguo à cápsula foi possível constatar, de modo constante, a mudança da cor das paratireóides, tornando-as amarronzadas e destacando-as entre o amarelo-ouro da gordura, impõe maior atenção ao cirurgião. Dessa forma, é absolutamente indispensável que na dissecção do lobo, esse restrito tecido gorduroso aderido à cápsula tireóidea seja sempre conservado (Figuras 4).

Após a retirada da peça cirúrgica, aí então, como uma ordem previamente estabelecida, as paratireóides retornam às posições descritas nos clássicos de anatomia (Figuras 4, 7).

Apesar de terem sido valorizados por Thompson ${ }^{17}$, não parece adequado insistir nos conceitos "tireoidectomia quase total" e "tireoidectomia sub-total", ambos oriundos dos anos cinqüenta, quando eminentes cirurgiões trabalhavam em condições técnicas desfavoráveis, inclusive realizando essas operações sob anestesia local. A lobectomia total e a lobectomia subtotal, esta última, uma das variáveis da tireoidectomia parcial, é o procedimento cirúrgico mínimo ${ }^{9,10}$, só são exequiíveis, com menores possibilidades de complicações, após as ligaduras dos pedículos arteriais e a preservações das paratireóides e dos nervos laríngeos recorrentes. A secção do ligamento de Berry permite dissecar o nervo laríngeo recorrente até a entrada laringe por baixo do músculo crico-tireóideo e liberar completamente o lobo. Com freqüência, essa secção do ligamento de Berry provoca sangramento muito próximo da entrada no nervo laríngeo na laringe, oriundo de arteríola do pericôndrio traqueal, que deve ser eletro-coagulado, exclusivamente, com bisturi bipolar.

A retirada do processo piramidal em monobloco à tireóide é indispensável tanto nas doenças benignas quanto nas malignas, especialmente nesta última, quando é desejada a completa exérese da tireóide junto ao esvaziamento cervical funcional, para tratamento complementar com I ${ }^{131}$. É importante assinalar esse procedimento adicional imposto pelos rigores expressos nos conceitos oncológicos. 
Apesar de discutível em alguns casos selecionados, todos os pacientes desta série receberam drenagem fechada por tempo variável entre um a dois dias, só sendo retirada quando o volume se mostrou inferior a $5 \mathrm{ml} / 24$ horas.

Mesmo com todos esses cuidados, que sem dúvida contribuem para evitar as complicações pós-operatórias, é possível que o patologista assinale o achado de uma paratireóide sub-capsular ou intra-tireóidea. Na primeira circunstância, é impossível a identificação pelo cirurgião. Todavia, para confirmar a ausência de paratireóide aderida à cápsula, especialmente, nos portadores de bócios de grande volume, mesmo com quatro paratireóides identificadas e preservadas, a tireóide ressecada é criteriosamente examinada. Se alguma estrutura sugestiva de paratireóide for vista, é separada e colocada no soro fisiológico: enquanto a gordura afunda, a paratireóide sobrenada. O sobrenadante, tratado como paratireóide, é fatiado em minúsculos fragmentos e implantado num túnel, obtido pelo afastamento das fibras musculares, na intimidade do terço médio do esternocleicomastóideo, seguido da síntese do fáscia.

Em três pacientes do sexo feminino que faziam reposição de cálcio por longo período, para tratamento de osteoporose, as paratireóides se apresentaram em menor tamanho, forçando maior cuidado na identificação, apesar de a mudança da cor durante o manuseio cirúrgico ter ocorrido como nos outros doentes.

Não há dúvidas de que após cem anos após a descrição anatômica das paratireóides persistem os estorvos para a identificação dessas glândulas no curso das tireoidectomias indicadas nos bócios e nos tumores, determinando hipoparatireoidismo pós-operatório ${ }^{20,21}$. É igualmente certo que os bócios de grande volume, inclusive os cervico-mediastínicos, os tumores malignos da tireóide que requerem as tireoidectomias totais com ou sem os esvaziamentos cervicais pressupõem maior difi- culdade na identificação das paratireóides e, dessa forma, maior possibilidade dos hipoparatireoidismos transitórios e persistentes ${ }^{22,23}$.

A experiência cirúrgica demonstra com extraordinária clareza que a escolha da via de acesso é de fundamental importância para evitar a complicação do hipoparatireoidismo após as tireoidectomias.

Desde que os doentes sejam devidamente aclarados quanto aos possíveis complicações das tireoidectomias, por meio das explicações do cirurgião e da assinatura do Termo de Consentimento Livre e Esclarecido, não há razão para que a via de acesso privilegie a estética em confronto com a segurança cirúrgica.

Decididamente, o uso da incisão de Kocher é inadequado nos bócios de grande volume. As incisões em U e a arciforme possibilitam maior segurança à equipe cirúrgica nas dissecções da tireóide, paratireóides e nervos laríngeos recorrentes, evitando a afoiteza operatória desnecessária ${ }^{23}$.

Além da escolha da via de acesso, torna-se indispensável os seguintes cuidados:

1. Para que se obtenha a mobilização do lobo em direção medial e, assim, a identificação das paratireóides, é indispensável proceder à ligadura do pedículo superior, seguida da do inferior; 2. Evitar pequenas hemorragias no campo cirúrgico; caso contrário, a identificação das paratireóides ficará muito mais difícil; 3 . O tecido adiposo irregular e esparso aderido à cápsula da tireóide deve ser sempre cuidadosamente preservado; 4 . As peças cirúrgicas das tireoidectomias, logo após a exérese, devem ser criteriosamente examinadas, especialmente a cápsula da face lateral e posterior, para identificação de paratireóide retirada de modo inadvertido. Se alguma for identificada, deve ser implanta no esternocleidomastóideo; 5. Proceder a exérese do processo piramidal em monobloco à tireóide tanto nas doenças benignas quanto nos tumores malignos.

\begin{abstract}
Background: The objective of this study is to establish an anatomical surgical protocol to guide on parathyroid identification. Method: This was a transversal and retrospective study using intraoperative photographic register of 53 total and partial thyroidectomies, done through January 2002 and August 2006, with benign and malignant thyroid patients. Results: Pictures of 111 parathyroids glands have been taken. From 67 superior parathyroids, 65 (97\%) were surrounded by a thin and irregular adipose tissue; from 44 inferior parathyroids, 41 (93.1\%) were partially or totally surrounded by fat adhered and spread to the thyroid capsule. The access and care to prevent hemorrhages are both items which prevent the surgeon from having greater difficulties. Furthermore, it is necessary to follow a rigid technique with ligature of the superior pedicle, carried out as the first step, followed by dislocation of thyroid lobe into a medial position to identify safely the parathyroids glands. Conclusion: It is mandatory to preserve the adipose tissue intact adhered to the thyroid capsule, where parathyroids glands are localized more than $90 \%$. The surgical handling of this thin adipose lamina provokes parathyroid color changes transforming them from yellow-gold fat to brownish and imposing bigger attention to the surgeon.
\end{abstract}

Key words: Parathyroid glands; Thyroid gland; Thyroidectomy.

\section{REFERÊNCIAS}

1. Beahrs OH, Hoehn JG. Surgery of the parathyroid glands. In: Loré JM. Head and neck surgery. Philadelphia: Harper \& Row Publishers; 1981. p. 1.
2. Abboud B. Anatomie topographique et vascularisation artérielle des parathyroïdes: application pratique. Presse Med. 1996; 25(25):1156-61.

3. Testut L, Latarjet A. Tratado de anatomia humana. Barcelona: Salvat. 1959. p.1052-60. 
4. Testut L, Jacob O. Tratado de anatomia topográfica. Barcelona: Salvat. 1952. p. 709.

5. Rouviere HD. Anatomie humaine descriptive, topographique et fonctionnelle. In: Anatomie tete et cou. v. 1. 12 ${ }^{\mathrm{a}}$ ed. Paris: Masson; 1984. p. 506-7.

6. Botelho JB, Cançado ARS, Sousa EA. Importância anatomocirúrgica das características macroscópicas, localização e suprimento vascular das glândulas paratireóides cervicais. Rev Col Bras Cir. 2004; 31(2):132-8.

7. Botelho JB, Anjos GS, Pires GP, Ferreira DMR, Leite TO, Resende GAS. Protocolo anatômicocirúrgico das relações entre os nervos laríngeos recorrentes e as artérias tireóideas inferiores: estudo em 79 tireoidectomias. Rev Col Bras Cir. 2007; 34(3):1426.

8. Cakmakli S, Aydintug S, Erdem E. Post-thyroidectomy hypocalcemia: does arterial ligation play a significant role? Int Surg. 1992; 77(4):284-6.

9. Botelho JB, Souza RM, Anjos GS, Cattebeck LCH. Patologia da glândula tireóide. In: Botelho JB. Otorrinolaringologia e cirurgia de cabeça e pescoço para estudantes. Manaus: Editora da Universidade Federal do Amazonas; 2000. p. 390-8.

10. Botelho JB, Souza RM, Anjos GS, Cattebeck LCH. Pathologie de la glande thyroïde. In: Botelho JB, Gehanno P. Otorhinolaryngologie et chirurgie cervico-faciale à l'usage dês étudiants. Paris: Edk; 2002. p. 86-9.

11. Manolidis S, Takashima M, Kirby M, Scarlett M. Thyroid surgery: a comparasion of outcomes between experts and surgeons in training. Otolaryngol Head Neck Surg. 2001; 125(1):30-3.

12. Orsemigo E, Beretta E, Veronesi P, Mari G, Gini P, Carlo VD. Total thyroidectomy in the treatment of thyroid cancer. Eur $\mathbf{J}$ Surg Oncol. 1995; 21(5):478-81.

13. Affleck BD, Swartz K, Brennan J. Surgical considerations and controversies in thyroid and parathyroid surgery. Otolaryngol Clin North Am. 2003; 36(1):159-87.

14. Fewins J, Simpson B, Miller FR. Complications of thyroid and parathyroid surgery. Otolaryngol Clin North Am. 2003; 36(1):189-206.

15. Steinmüller T, Klupp J, Wenking S, Neuhaus P. Complications associated with different surgical approaches to differentiated thyroid carcinoma. Langenbecks Arch Surg. 1999; 384(1):50-3.
16. Bergamaschi R, Becouarn G, Ronceray J, Arnaud, JP. Morbidity of thyroid surgery. Am J Surg. 1998; 176(1):71-5.

17. Bliss RD, Gauger PG, Delbridge LW. Surgeon's approach to the thyroid gland: surgical anatomy and the importance of technique. World J Surg. 2000; 24(8): 891-7.

18. Botelho JB, Cattebeke LCH, Cettebeke TMH, Anjos, GS, Oliveira VS, Lima, RM, Barbosa, MF, Aguiar, GM. Histopathologie de 573 thyroïdectomies réalisées entre 1976 a 1998 ManausBrésil. Oto-Rhino-Laryngologie Française. 2001;66(2):47-9.

19. Testini M, Gurrado A, Lissidini G, Nacchiero M. [Hypoparathyroidism after total thyroidectomy]. Minerva Chir. 2007; 62(5):409-16.

20. Asari R, Passler C, Kaczirek K, Scheuba C, Niederie B. Hypoparathyroidism after total thyroidectomy: a prospective study. Arch Surg. 2008; 143(2):132-7.

21. Lombardi CP, Raffaelli M, De Crea C, Traini E, Oragano L, Sollazzi L, Bellantone R. [Complications in thyroid surgery]. Minerva Chir. 2007; 62(5):395-408.

22. Page C, Strunski V. Parathyroid risk in total thyroidectomy for bilateral, benign, multinodular goitre: reporto f 351 surgical cases. J Laryngol Otol. 2007; 121(3):237-241.

23. Botelho JB. Incisão em U: nova via de acesso aos bócios de grande volume. Prêmio e Medalha Franz Escher. Centenário de Kocher. $94^{\circ}$ Congresso Suíço de Otorrinolaringologia e Cirurgia Cervico-facial. Berna. 2007.

Como citar este artigo:

Botelho JB, Anjos GS, Gomes JM F ${ }^{\mathbf{o}}$, Pires GP, Ferreira DM, Melo e Souza FB, Leite TO. Relações anatômicas das glândulas paratireóides cervicais com a tireóide: estudo em 53 tireoidectomias. Rev Col Bras Cir. [periódico na Internet] 2008; 35(2). Disponível em URL: http:/ /www.scielo.br/rcbc

Endereço para correspondência:

João Bosco Lopes Botelho

Av. Eduardo Ribeiro, 520 - sala 705 - Centro

69010-000 - Manaus - AM

Tel. (92) 9981-6199 - (92) 3234-5609

E-mail: joaoboscobotelho@gmail.com 